\title{
El papel del turismo patrimonial en el índice de competitividad turística regional de Colombia: una evaluación de las relaciones mediante PLS-PM ${ }^{1}$
}

\author{
José Mauricio Gil-León ${ }^{2}$ \\ Universidad Pedagógica y Tecnológica de Colombia - UPTC \\ josemauricio.gil@uptc.edu.co \\ Jhancarlos Gutiérrez-Ayala ${ }^{3}$ \\ Universidad Pedagógica y Tecnológica de Colombia - UPTC \\ jhancarlos.gutierrez@uptc.edu.co \\ Edgar Alonso Ramírez-Hernández ${ }^{4}$ \\ Universidad de los Andes \\ ea.ramirezh@uniandes.edu.co
}

Fecha de recepción: 18 de noviembre de 2020

Fecha de aprobación: 11 de mayo de 2021

Fecha de publicación: 05 de agosto de 2021

Cómo citar este artículo / To reference this article / Comment citer cet article / Para citar este artigo:

Gil-León, J. M.; Gutiérrez-Ayala, J.; Ramírez-Hernández, E. A. (2021). El papel del turismo patrimonial en el índice de competitividad turística regional de Colombia: una evaluación de las relaciones mediante PLS-PM. Revista Escuela de Administración de Negocios, (90), 169-192. DOI: https://doi.org/10.21158/01208160.n90.2021.2973

\section{Resumen}

La relación entre el patrimonio cultural y el desarrollo económico de un territorio se explica cuando intermedian la cadena de valor turística, los factores endógenos del destino -como la tradición culturaly los factores de soporte -infraestructura y condiciones políticas-. En este contexto es importante reconocer las dinámicas propias de los destinos, ya que estas permiten crear ventajas competitivas para así tomar la delantera con respecto a los competidores directos al momento de atraer turistas. Este artículo presenta una revisión metodológica del Índice de Competitividad Turística Regional de Colombia para las ciudades capitales, con el propósito de evaluar el desempeño de las ciudades y las relaciones existentes entre los factores endógenos, la cadena de valor turística y las condiciones económicas y sociales. Lo anterior se lleva a cabo mediante el método de Partial Least Squares-Path Modeling, con el fin de establecer relaciones entre variables no observables a partir de valores evaluados en escala de Likert. Los resultados muestran que existe una relación positiva entre el aprovechamiento del patrimonio cultural y la competitividad de un destino turístico. Bogotá, Medellín y Cartagena son las ciudades con mejor desempeño global, debido

1 Artículo resultado del proyecto de investigación «Diseño de un modelo de gobernanza a través de la apropiación social del patrimonio cultural como estrategia de desarrollo económico local desde la actividad turística en la ciudad de Tunja». Financiado por el Ministerio de Ciencia, Tecnología e Innovación, contrato 181 de 2019.

2 Economista, especialista en finanzas y magíster en economía de la Universidad Pedagógica y Tecnológica de Colombia. ORCID: https://orcid.org/0000-0002-5653-5245

3 Economista y estudiante de la maestría en economía de la Universidad Pedagógica y Tecnológica de Colombia. Joven Investigador Grupo CREPIB. ORCID: https://orcid.org/0000-0002-4756-7683

4 Economista de la Universidad Pedagógica y Tecnológica de Colombia y estudiante del doctorado en economía de la Universidad de los Andes. ORCID: https://orcid.org/0000-0003-3786-5051 
a la buena estructura de soporte que se da a la cadena turística y a las condiciones políticas. En ciudades con alto nivel patrimonial como, por ejemplo, Tunja o Popayán, se evidencian problemas en el desempeño por las condiciones de infraestructura, mercadeo y gestión del destino, lo que les impide aprovechar sus capacidades.

Palabras clave: turismo patrimonial; competitividad turística; competitividad territorial; industria turística; infraestructura turística; turismo en Colombia; cadena de valor turística; patrimonio cultural.

\title{
The role of heritage tourism in the Regional Tourism Competitiveness Index in Colombia: an assessment of the relationships by using the PLS-PM
}

\begin{abstract}
The relationship between cultural heritage and economic development of a territory is explained when the tourism value chain, endogenous factors of the destination — such as cultural tradition —, and supporting factors - infrastructure and political conditions - intervene. In this context, it is important to recognize the dynamics that are particular to the destinations, as these allow creating competitive advantages to take the lead over direct competitors when attracting tourists. This article presents a methodological review of the Regional Tourism Competitiveness Index in Colombia for capital cities, with the purpose of evaluating the performance of cities and the existing relationships between endogenous factors, the tourism value chain, and the economic and social conditions. This is carried out by using the Partial Least Squares-Path Modeling method, with a view to establish relationships among unobservable variables based on values that were evaluated on a Likert scale. The results show that there is a positive relationship between the use of cultural heritage and the competitiveness of a tourist destination. Bogota, Medellin, and Cartagena are the cities with the best overall performance, due to the good support structure given to the tourism chain and political conditions. Cities with a high level of heritage, such as Tunja or Popayán, signal performance problems attributed the conditions of infrastructure, marketing, and destination management, which prevent them from taking advantage of their capabilities.
\end{abstract}

Keywords: heritage tourism; tourism competitiveness; territorial competitiveness; tourism industry; tourism infrastructure; tourism in Colombia; tourism value chain; cultural heritage. 


\section{O papel do turismo patrimonial no índice de competitividade do turismo regional da Colômbia: uma avaliação das relações usando o PLS-PM}

\section{Resumo}

A relação entre o patrimônio cultural e o desenvolvimento econômico de um território se explica quando a cadeia de valor do turismo é mediada pelos fatores endógenos do destino — como a tradição cultural- e pelos fatores de suporte —infraestruturas e condições políticas-. Neste contexto, é importante reconhecer a dinâmica dos destinos, uma vez que esta permite a criação de vantagens competitivas assumindo a liderança em relação aos concorrentes diretos na atração de turistas. Este artigo apresenta uma revisão metodológica do Índice de Competitividade Turística Regional da Colômbia para as capitais, com o objetivo de avaliar o desempenho das cidades e as relações entre os fatores endógenos, a cadeia de valor do turismo e as condições econômicas e sociais. Isso é feito por meio do método Partial Least Squares-Path Modeling, a fim de estabelecer relações entre variáveis não observáveis a partir de valores avaliados na escala Likert. Os resultados mostram que existe uma relação positiva entre o uso do patrimônio cultural e a competitividade de um destino turístico. Bogotá, Medellín e Cartagena são as cidades com melhor desempenho global, devido à boa estrutura de apoio que se dá à cadeia turística e às condições políticas. Em cidades com alto nível de patrimônio, como Tunja ou Popayán, os problemas de desempenho são evidentes devido às condições de infraestrutura, marketing e gestão do destino, que impedem o aproveitamento de suas capacidades.

Palavras-chave: turismo patrimonial; competitividade turística; competitividade territorial; indústria turística; infraestrutura turística; turismo na Colômbia; cadeia de valor turístico; patrimônio cultural.

\section{Le rôle du tourisme patrimonial dans l'indice de compétitivité du tourisme régional en Colombie: une évaluation des relations à l'aide du PLS-PM}

\section{Résumé}

La relation entre patrimoine culturel et développement économique d'un territoire s'explique lorsque la chaîne de valeur touristique est complétée par des facteurs endogènes de la destination — tels que la tradition culturelle - et des facteurs sous-jacents - infrastructures et conditions politiques-. Dans ce contexte, il s'agit de reconnaître la dynamique des destinations permettant la création d'avantages compétitifs sur les concurrents directs pour attirer les touristes. Cet article présente une revue méthodologique de l'indice de compétitivité touristique des capitales régionales colombiennes, dans le but d'évaluer la performance des villes et les relations entre les facteurs endogènes, la chaîne de valeur touristique et les conditions économiques et sociales. Ce travail est réalisé via la méthode de modélisation des moindres carrés partiels permettant d'établir des relations entre des variables non observables à partir de valeurs évaluées sur une échelle de Likert. Les résultats montrent qu'il existe une relation positive entre l'utilisation du patrimoine culturel et la compétitivité d'une destination touristique. Bogotá, Medellín et Carthagène sont les villes avec les meilleures performances globales grâce au bon état des structures sous-jacentes apporté à la chaîne touristique. Dans les villes à fort potentiel patrimonial, comme Tunja ou Popayán, les déficits de performance sont crées en raison des conditions d'infrastructure, de commercialisation et de gestion de la destination les empêchant de tirer parti de leur attractivité

Mots-clés: tourisme patrimonial; compétitivité touristique; compétitivité territoriale; industrie touristique; infrastructures touristiques; tourisme en Colombie; chaîne de valeur touristique; patrimoine culturel. 


\section{Introducción}

$\mathrm{E}^{1}$ patrimonio y el turismo patrimonial se han establecido a nivel mundial como industrias claves para el desarrollo de las regiones. Los estudios de Dwyer y Kim (2003), Ritchie y Crouch (2003), Sasaki (2010), Alberti y Giusti (2012), entre otros, manifiestan la importancia que tiene el patrimonio cultural y la cadena turística de un destino sobre la generación de procesos de crecimiento en el territorio. En este sentido, el turismo resulta central en el aprovechamiento de los factores endógenos patrimoniales, ya que este sector es capaz de generar clústeres y encadenamientos a partir del patrimonio y la culturas.

Un rápido análisis de los modelos que relacionan cultura y patrimonio, turismo y competitividad del territorio, a nivel mundial, permite identificar un posicionamiento en las ideas de Porter (1980; 1985; 1990; 2008), de manera que se recojan propuestas tales como ventajas competitivas, competitividad sistémica, fuerzas competitivas y factores endógenos y de soporte; estas propuestas se amplían más adelante. Sin embargo, preliminarmente vale la pena aclarar que estas aparecen como respuesta a la idea de establecer relaciones o causalidades en la interacción entre tres variables fundamentales: patrimonio, cadena de valor turística y desarrollo del destino.

En el caso de Colombia se destacan dos iniciativas que procuran identificar los factores y proponer estrategias en lo que se refiere a la interacción de las tres variables mencionadas. Por una parte, el Instituto Distrital de Turismo de Bogotá (2014) presenta un estudio sustentado en la competitividad sistémica ${ }^{6}$, el cual propone una serie de indicadores de evaluación para analizar el impacto del turismo en la ciudad; los indicadores van desde la conformación de la cadena - factores creados, hoteles, restaurantes, agencias de viajepasando por la evaluación de factores de soporte -infraestructura, servicios de comercio, política pública一, hasta indicadores de impacto como la generación de valor agregado en el sector.

Por otra parte, desde el 2015 el Centro de Pensamiento Turístico de Colombia (CPTUR) ${ }^{7}$ ha construido el Índice de Competitividad Turística Regional de Colombia (ICTRC), el cual tiene como objetivo «registrar y medir los factores asociados a la competitividad de la actividad turística, cuyos resultados permitan a las autoridades departamentales la priorización de las políticas y proyectos» (Centro de Pensamiento Turístico de Colombia, 2019a, p. 3). Este índice recoge dimensiones asociadas a factores endógenos, creados y de soporte ${ }^{8}$ que participan en la capacidad que tienen para competir los destinos turísticos nacionales. Este índice es calculado para 30 departamentos, 21 ciudades capitales y 81 municipios con vocación turística9

5 Véase al respecto Vasenska (s. f.).

6 Análisis desde la competitividad que analiza la relación de la empresa en la perspectiva meta — factores socioculturales, organización política, jurídica y económica de un territorio —, meso — política regional, sistema educativo y tecnológico —, micro — capacidad de gestión, estrategias empresariales, redes empresariales_y macro — política monetaria y fiscal— (Esser et al., 1996).

7 Centro de investigación para el análisis y la reflexión sobre el sector turístico en Colombia, el centro de información se creó con el trabajo cooperativo entre la Asociación Hotelera y Turística de Colombia (Cotelco) y la Fundación Universitaria Cafam (Unicafam).

8 El ICTRC evalúa las dimensiones cultural, ambiental, gestión de destino, económica, empresarial, estrategia de mercadeo, social e infraestructura.

9 Los departamentos evaluados son: Bogotá —Distrito Capital—, Bolívar, Valle del Cauca, Antioquia, Risaralda, Quindío, Atlántico, Santander, Caldas, Cundinamarca, Magdalena, Cauca, Boyacá, Tolima, Huila, Meta, Norte de Santander, San Andrés y Providencia, Nariño, Caquetá, La Guajira, Casanare, Amazonas, Sucre, Cesar, Vaupés, Córdoba, Guaviare, Vichada, Putumayo y Arauca (Centro de Pensamiento Turístico de Colombia, 2019b). Las ciudades capitales evaluadas son: Bogotá, Medellín, Cartagena, Cali, Barranquilla, Pereira, Bucaramanga, Santa Marta, Manizales, Ibagué, Popayán, Armenia, Tunja, Cúcuta, Villavicencio, Neiva, Pasto, Florencia, Riohacha, Mitú y Puerto Inírida (Centro de Pensamiento Turístico de Colombia, 2019a). 
El ICTRC es una herramienta que permite evaluar cómo compiten los destinos en las diferentes dimensiones evaluadas, de manera que establece una medición acertada de la competitividad, calificando las condiciones sobresalientes o deficientes de un territorio. Sin embargo, cuando se plantea el estudio de las dinámicas entre patrimonio, empresas turísticas, competitividad ${ }^{10}$ $y$ otras dimensiones asociadas, el ICTRC no logra tener alcance. Además, cuando el objetivo es llegar a plantear relaciones de causalidad entre dimensiones, con el fin de establecer estrategias sectoriales en un destino turístico en Colombia no es posible tomarlo como herramienta.

En este sentido, este documento se presenta como una reinterpretación metodológica del ICTRC que pretende establecer no solo la medición de la competitividad, sino llegar a un índice particular para cada variable estudiada, además de las relaciones entre estas, para así posibilitar la formulación de políticas que puedan impactar aspectos específicos del sector. La revisión metodológica parte de los planteamientos de Dwyer y Kim (2003), Dwyer, Livaic y Mellor (2003) y Enright y Newton (2004), quienes combinan las ideas de ventajas comparativas, ventajas competitivas y competitividad sistémica para explicar relaciones entre las dimensiones geográfica, social, política y económica.

La estimación del nuevo sistema de índices - uno para cada dimensión - se realiza a través de la metodología Partial Least Squares-Path Modeling (PLSPM) que, además de permitir el cálculo de los índices, estima las correlaciones entre las dimensiones, con lo cual logra validar un conjunto de hipótesis de relación entre dimensiones propuestas. El ejercicio se realiza para las ciudades capitales evaluadas originalmente por el ICTRC.

El artículo se divide en seis partes, incluida esta introducción. En la segunda parte se presenta la construcción teórica de la relación entre patrimonio, empresas turísticas, competitividad y otras dimensiones asociadas. En la tercera se presenta el sistema de hipótesis que constituye el modelo a estimar mediante la metodología PLS-PM. En la cuarta se presentan los resultados de estimación de los índices y la validación de hipótesis de relación entre dimensiones. En la quinta se presenta una discusión de resultados en la que se analizan los índices e hipótesis validadas. Finalmente, se presentan las conclusiones.

\section{Construcción teórica}

工asociado al componente de comparación - y multidimensional —asociado a las características o cualidades de la competitividad-(Spence y Hazard, 1988). Young (1986) y Cho (1998) proponen, desde una perspectiva macroeconómica, que la competitividad es un asunto nacional cuyo último objetivo es mejorar el ingreso de la población, así como generar procesos que permitan también mejorar el bienestar y los estándares de vida de la población, considerando las condiciones de libre mercado - comercio, producción e inversión-.

Cuando se pretende «reducir» el concepto de competitividad desde la condición nacional a lo territorial, este se modifica parcialmente y se adapta a la capacidad de las empresas de entrar en un escenario de competencia internacional y permanecer en este mediante la atracción de

\footnotetext{
${ }^{10}$ Las cuales, para este documento, se consideran «dimensiones fundamentales de análisis», dada su importancia remarcada en la mayoría de modelos de competitividad turística.
} 
demanda (Cuervo, 1993). Sin embargo, Porter (2008) propone que la competitividad no es una condición que depende únicamente de las empresas, sino que los territorios también compiten y dependen de la capacidad de los actores territoriales de aprovechar las condiciones naturales del territorio - ventajas comparativaspara generar clústeres o sistemas empresariales robustos - ventajas competitivas-.

El modelo de competitividad territorial más referenciado en estudios de turismo es el «diamante de Porter», el cual propone cuatro condiciones que determinan la competitividad de un territorio. Las condiciones las resumen Alberti y Giusti (2012): a) estrategia de la firma, demuestra la capacidad para competir en mercados internos y las condiciones propias del sistema empresarial; b) condiciones de los factores, relacionada con las estructuras físicas y administrativas, capital humano y capital empleado; c) condiciones de demanda, refleja las características de la demanda y se relaciona con el impulso externo a la innovación empresarial; y d) industrias de soporte al clúster empresarial.

Con respecto a la competitividad de los territorios, Kresl y Singh (1999) afirman que, al hablar de territorio competitivo, el análisis no se limita a fronteras nacionales, sino que regiones -e incluso ciudades - pueden llegar a entrar en la competencia, si se considera que «las regiones y ciudades compiten por la atracción y retención de recursos debido a que el entorno local afecta el desempeño de las empresas» (Ibarra-Armenta y Trejo-Nieto, 2014). En este escenario es posible identificar «regiones ganadoras» $y$ «regiones perdedoras», al ser características de las primeras conseguir atracción y retención de flujos de inversión, mantener altas tasas de crecimiento y contar con alta competitividad en escenarios de mercados internacionales posicionando productos con altos niveles de valor agregado.

Una vez se logra la aproximación a la condición de la competitividad territorial, se procede a plantear la idea de la competitividad turística de los territorios. Al respecto se toman como punto de entrada las ideas de Dwyer y Kim (2003), quienes proponen un modelo de competitividad turística que se fundamenta en dos principios básicos: a) los territorios cuentan con ventajas comparativas representadas en su medio ambiente, su cultura y su patrimonio; $y b$ ) las ventajas competitivas se evidencian a través del desempeño empresarial de la cadena de valor del turismo y sus factores de soporte. En este orden de ideas, se procede a estudiar las relaciones entre ventajas comparativas patrimoniales y naturales, clúster turístico y competitividad del destino.

El estudio de la relación entre patrimonio cultural y la competitividad de un destino turístico es un tema con vacíos teórico-prácticos hasta la fecha (Alberti y Giusti, 2012). Estos vacíos se hacen explícitos cuando entra en consideración la intermediación del turismo como sector que aprovecha el patrimonio y puede generar procesos de crecimiento y desarrollo regional. Hong (2009) califica la competitividad en la industria turística como «multidimensional y compleja», considerando que el concepto contiene diferentes significados, perspectivas y mediciones, además de que fusiona condiciones económicas y administrativas.

Según Alberti y Giusti (2012), «el turismo, es una de las industrias más relevantes del mundo, desempeña un papel clave en el desarrollo y la competitividad de muchas regiones». A esto se suma que existen algunas condiciones propias de los territorios representadas en el patrimonio -tangible e intangible- y la cultura. Estas condiciones contribuyen a la generación de procesos de innovación y competitividad a través de la industria turística.

Según el Centro de Pensamiento Turístico de Colombia, el turismo desempeña un papel fundamental en la relación patrimoniocompetitividad; esto porque $\ll[\ldots]$ los activos culturales pueden atraer el turismo a un destino específico, y el turismo puede aportar nuevos y frescos recursos al sector cultural y a toda la región, 
creando clústeres y, por lo tanto, fomentando la competitividad» (2020). Para Enright y Newton (2004), el paso de patrimonio a competitividad a través del clúster turístico se consigue cuando el destino puede atraer y satisfacer a los turistas y se potencia cuando los prestadores de servicios turísticos aprovechan las condiciones propias del destino.

El papel de los clústeres es fundamental en la competitividad porque con estos se posibilita la generación de innovaciones. Claro es que, más allá de las relaciones entre firmas, se plantea la necesidad de establecer relación con instituciones públicas y académicas. Esto permite dar claridad a las exigencias de la demanda canalizando el conocimiento y la información necesarias para conseguir procesos estables de crecimiento (Alberti y Giusti, 2012).

$\mathrm{Al}$ igual que con la competitividad, en general, el papel de la competitividad turística se posiciona en el territorio y de forma específica en el destino, en este caso las ciudades, las cuales son calificadas por Scott (1997) como centros en los que se desarrollan capacidades culturales representadas en arte, ideas y estilos. Adicionalmente, es en las ciudades donde las empresas compiten y pueden aprovechar las condiciones de soporte de los territorios.

Cuando se analiza la relación entre patrimonio y competitividad se encuentran varios estudios que proponen variables e indicadores que tienen algún grado de incidencia, los cuales pueden ser: las condiciones del medio ambiente, la política de la mano de la infraestructura de las ciudades, la percepción de los turistas, el marketing y la publicidad de los destinos, entre otras. En este escenario los modelos realizados por Dwyer y Kim (2003), Crouch y Ritchie (2006), así como por Hong (2009) y Sasaki (2010), establecen una serie de factores que interactúan en un destino turístico y definen el puente del potencial patrimonial con la competitividad.

Tabla 1. Factores de evaluación de la competitividad

\begin{tabular}{|l|l|}
\hline Factores endógenos & $\begin{array}{l}\text { Condiciones naturales o propias del territorio: } \\
\text { - clima } \\
\text { - los bienes patrimoniales } \\
\text { - geografía }\end{array}$ \\
\hline Factores creados & $\begin{array}{l}\text { Factores construidos en el territorio y que posibilitan la explotación de las potencialidades: } \\
\text { - indicadores en infraestructura para el turismo } \\
\text { - potencial de actividades — eventos culturales de la ciudad- } \\
\text { - shopping y entretenimiento - relacionado con las actividades complementarias a la } \\
\text { actividad turística- }\end{array}$ \\
\hline Factores de soporte & $\begin{array}{l}\text { En los factores que soportan la experiencia turística se considera la interacción de cinco } \\
\text { actores: ambiente, sector público, sector privado, academia y sociedad civil. } \\
\text { Se considera los indicadores de publicidad: preferencias del mercado, la hospitalidad de la } \\
\text { ciudadanía para con los turistas, políticas públicas de incentivo sectorial y las condiciones de } \\
\text { competitividad interno de las empresas en temas de recurso humano y capacidades. }\end{array}$ \\
\hline Análisis de demanda & $\begin{array}{l}\text { La forma de reflejar la interacción de los factores mencionados y su efecto directo en el } \\
\text { crecimiento económico es a través del análisis de demanda. } \\
\text { Un estudio de los gastos e ingresos realizados por los turistas, por lo que conocen: iquiénes } \\
\text { nos visitan?, icuáles son sus motivos?, icuánto gastan?, y iqué efecto se genera sobre el } \\
\text { patrimonio? }\end{array}$ \\
\hline
\end{tabular}

Fuente. Elaboración propia. 
Los factores presentados se basan en la estructura propuesta por el diamante de Porter, de manera que estos postulados proponen que la competitividad de una industria, en este caso el turismo, depende de la fuerza relativa de la economía, representada en el clúster empresarial y en una serie de condiciones o factores como, por ejemplo, las industrias de soporte, el Estado y las condiciones de demanda (Ritchie y Crouch, 2003). Además, consideran algunos postulados desde la competitividad sistémica, tales como las condiciones políticas y sociales del territorio, las cuales, según la Organización Mundial de Turismo (2005) y el Instituto Distrital de Turismo de Bogotá (2014) son determinantes a la hora de evaluar la competitividad turística del destino.

Una vez presentados los factores generales que determinan la competitividad turística de un destino, se da paso a plantear las variables específicas que pueden considerarse condicionantes, entre las que se encuentran el patrimonio, la estructura empresarial, el marketing, la gestión del territorio, el desempeño político, la publicidad y las condiciones propias de la expresión de la competitividad, representadas en variables sociales y económicas.

\subsection{Patrimonio y medio ambiente}

La primera condición, la patrimonial y medioambiental, toma las condiciones propias del destino en cuanto a cultura, eventos, bienes culturales reconocidos, historia, clima, flora y fauna (Dwyer y Kim, 2003; Dwyer, Forsyth y Rao, 2000). Según los planteamientos de Cohen (1988), y los de Murphy, Pritchard y Smith (2000), el patrimonio y la cultura de un destino, representados en instituciones, arquitectura, gastronomía, arte, música y danza, brindan soporte a la competitividad y permiten al clúster empresarial explotar este potencial, así como otorgan un poder básico para pasar de ventajas comparativas a constituir ventajas competitivas.
Investigaciones previas, como la de Hesmondhalgh (2007), muestran que existe una relación positiva entre el patrimonio cultural y el desempeño económico de una región. En este escenario se proponen tres hipótesis a validar:

- Hipótesis base: las condiciones patrimoniales de un destino turístico impactan positivamente en la generación de competitividad en el territorio.

- Hipótesis 1: las variables culturales y patrimoniales favorecen a la creación de la cadena de valor turística en un territorio.

- Hipótesis 2: las condiciones ambientales del destino favorecen a la estructura de la cadena de valor turística en el territorio.

\subsection{Empresarial y mercadeo}

Según Alberti y Giusti (2012), existen dos formas para aprovechar las condiciones patrimoniales de un destino: una por la vía política en cuanto a la participación del Estado y la formulación de políticas públicas sectoriales, y la segunda a partir de la constitución de emprendimientos y clústeres de prestadores de servicios turísticos que hagan uso de los factores culturales y naturales del territorio. En este escenario se reconoce que las empresas turísticas desempeñan un papel fundamental en la creación de sinergias empresariales, la constitución de procesos de competitividad empresarial y la presencia en el mercado a través de estrategias de marketing, asistencia a ferias turísticas y la presentación de productos por medio de canales físicos y digitales; así, procuran procesos de generación de oportunidades dirigidos a la población y el crecimiento de la economía. En este sentido es posible plantear cuatro hipótesis a validar:

- Hipótesis 3a: la cadena de valor turística realiza procesos positivos de mercadeo del territorio.

- Hipótesis 3b: la cadena de valor turística genera mejoras en los indicadores sociales del territorio. 
- Hipótesis 3c: la cadena de valor turística aporta de forma significativa a los indicadores económicos del territorio.

- Hipótesis 4: los procesos de mercadeo del destino aportan al crecimiento económico del territorio.

\subsection{Gestión del destino}

La gestión del destino, según Crouch y Ritchie (2006), se refiere a los factores que pueden fortalecer la calidad y las condiciones de apoyo del destino, condiciones de seguridad, presencia de policía, accidentalidad, gestión de marketing, planeación y desarrollo representado en la gestión ambiental y de recursos ambientales. En cuanto a estas condiciones se postula la siguiente hipótesis.

- Hipótesis 5: la gestión del destino y la experiencia del turista mejora los indicadores sociales del territorio.

\subsection{Infraestructura}

Para Dwyer y Kim (2003), los denominados «edificios» son esenciales para hacer que el turismo «pase». Esta variable considera dos aspectos. El primero de carácter de accesibilidad respecto a la existencia de aeropuerto, carreteras y el estado de estas. El segundo se refiere a las condiciones de infraestructura en tema de puentes, señalización y el estado arquitectónico en general ${ }^{11}$. Investigaciones como la realizada por Buhalis (2001) muestran que esta es una variable fundamental cuando se quiere observar el impacto del turismo sobre la competitividad, pues demuestra que en varias ciudades de Grecia es este el factor más débil y cómo genera fallos en el desempeño de la industria.

- Hipótesis 6: la infraestructura del destino turístico patrimonial mejora los indicadores de crecimiento económico del territorio.

\subsection{Política}

De acuerdo con la perspectiva de Porter, el papel del gobierno es importante porque su participación es fundamental en la generación de las condiciones para el desarrollo de las actividades turísticas. El papel del Estado es la generación de condiciones de educación, bienes públicos, servicios de soporte, políticas públicas de incentivo sectorial y condiciones tributarias de las empresas turísticas. El gobierno participa en la regulación de los mercados y el incentivo empresarial, además de la inversión en proyectos de turismo.

- Hipótesis 7: las políticas públicas de protección del patrimonio y fortalecimiento turístico del territorio favorecen el crecimiento económico del destino.

\subsection{Social}

El efecto de la industria turística no solo se refleja en variables económicas como el valor agregado, las condiciones de mejora de bienestar y la calidad de vida de la población, sino que conforman una parte importante del análisis. Desde las condiciones asociadas al mercado laboral se espera que la industria turística aporte a mejorar indicadores de mercado laboral, de modo que reduzcan la informalidad. A esto se adiciona la educación, por lo que una estructura turística, según el CPTUR (2020), debe procurar la apertura de programas de formación tanto en pregrado como en posgrado.

El modelo de competitividad de Dwyer y Kim (2003) propone que los efectos sobre el mercado laboral y la educación se reflejan en el desempeño de la economía del destino turístico. En este escenario se propone la siguiente hipótesis:

- Hipótesis 8: las condiciones sociales del destino generan un impacto positivo sobre los indicadores económicos.

\footnotetext{
${ }^{11}$ Referente al estado de conservación de las edificaciones.
} 
Con base en los factores y las hipótesis propuestos se plantea el modelo teórico a estimar (véase la Figura 1).

Figura 1. Modelo teórico

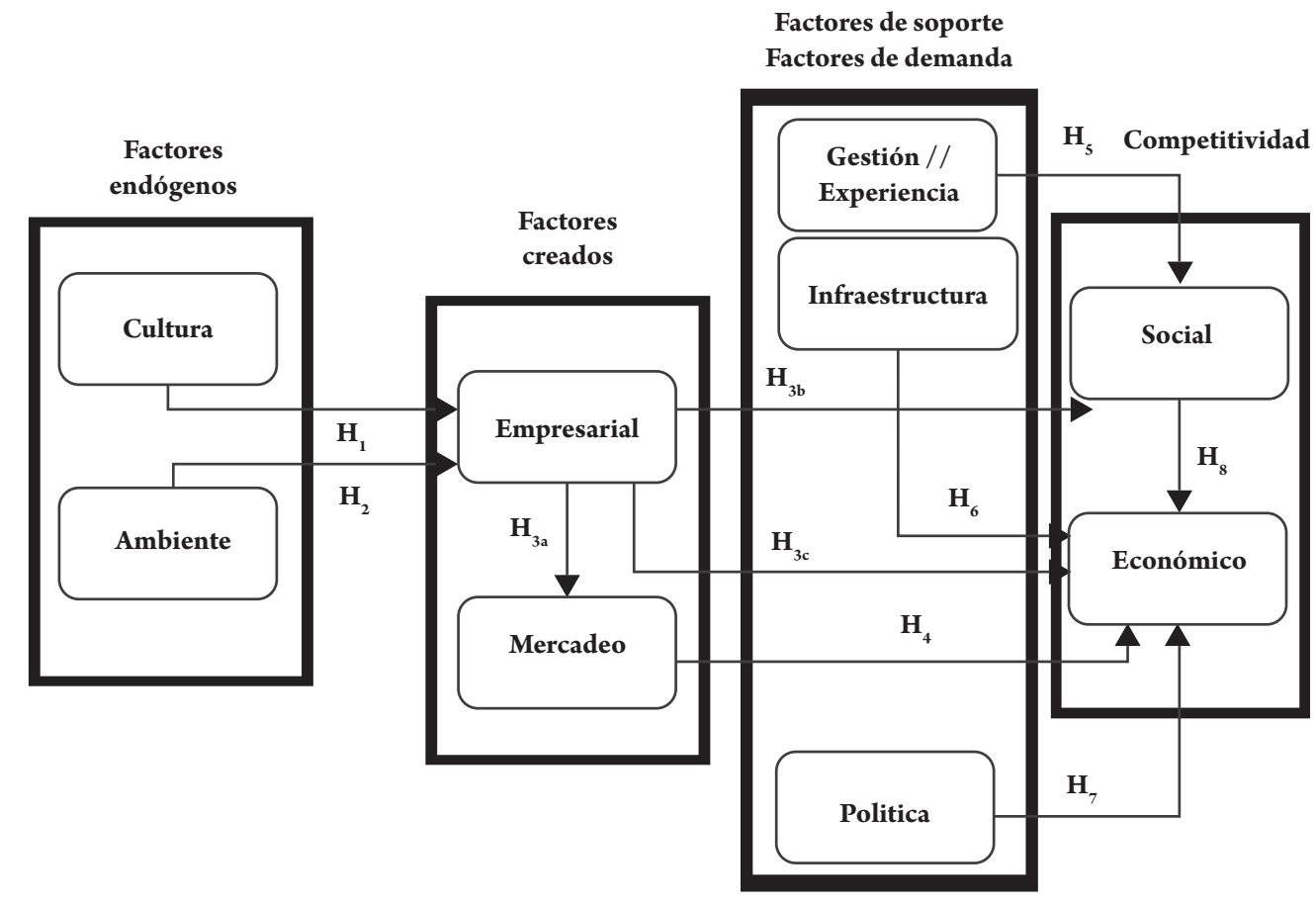

Fuente. Elaboración propia.

\section{Metodología}

$\mathrm{L}$ a construcción de los índices de desempeño y la validación de las hipótesis se lleva cabo con información de las 21 ciudades capitales evaluadas por el ICTRC, mediante el uso de la relación entre las variables cultura, ambiente, estructura empresarial turística, mercadeo y publicidad del destino, gestión, infraestructura, política y desempeño económico y social. La medición de las variables se realiza aceptando la evaluación presentada en el documento realizado por el CPTUR (2019a), en el que se consideran ocho dimensiones mediante 83 indicadores, en una escala de 0 a 10, los cuales se construyen a partir de información obtenida por la Asociación Hotelera y Turística de Colombia (Cotelco) y la Fundación Universitaria Cafam (Unicafam).
Con base en los 83 indicadores se procede a reestructurar los grupos para crear las nueve variables latentes-variables cualitativas o no observables- constituidas en el apartado teórico. Una vez construidos los nuevos grupos de indicadores para cada variable se procede a realizar un análisis factorial confirmatorio (AFC) mediante la evaluación del coeficiente de alfa de Cronbach y el rho de Dillon-Goldstein, los cuales permiten establecer la pertinencia de los indicadores - variables observadas - para explicar a los constructos - variables latentes-. Entre estos constructos se encuentran: el grado de validación de los indicadores - se hace cuando el alfa de Cronbach y el rho de Dillon-Goldstein son superiores a 0,7-. La evaluación se realiza para los 83 indicadores; después 
de validar la pertinencia y el grado de redundancia estadistica se eliminan 41 indicadores, de modo que se mantienen 42 para la estimación.

Una vez se validan los indicadores pertenecientes a cada uno de los ocho constructos se procede a la estimación de los índices y la validación de las hipótesis de relación. Para esto se usa la metodológia PLS-PM, la cual emplea elementos propios de la regresión, análisis de correlaciones, análisis de componentes principales y evaluación de ecuaciones estructurales (Sánchez, 2013). Según Garson (2016), la estimación consiste en una regresión en dos etapas: en la primera se construyen los índices para cada variable latente o constructo a partir de su respectivo bloque de indicadores. Esta etapa se conoce como estimación del modelo externo -outer model-; de forma funcional se presenta como:

$$
L V_{K}=f\left(X_{1}, X_{2}, X_{3}, \ldots, X_{n}\right)(a)
$$

En la segunda etapa se procede a validar las hipótesis de las relaciones planteadas, lo cual se realiza a partir de los índices calculados en la Etapa 1. Esta etapa se conoce como validación del modelo interno - inner model-. En ella se pretende calcular los estimadores de la relación entre constructos exógenos y endógenos no observables. En forma funcional se define:

$$
L V_{K}=f\left(L V_{1}, L V_{2}, L V_{3}, \ldots, L V_{n}\right)
$$

Las hipótesis propuestas para este caso particular permiten estructurar un sistema de cuatro ecuaciones, al ser las variables endógenas: el sistema empresarial turístico, el mercadeo y la publicidad del destino, el índice de impacto social y el índice de impacto económico; estas variables endógenas construyen un sistema de ecuaciones (c) que se estima tras la finalización de la Etapa 1 —cálculo del moderno externo-.

$$
\begin{gathered}
\text { Sis. Empresarial }=\beta_{0}+\beta_{1} \text { Cultura }+\beta_{2} \text { Ambiente }+u \\
\text { Mercadeo }=\alpha_{0}+\alpha_{1} \text { Sis. Empresarial }+v \\
\text { Impacto Social }=\gamma_{0}+\gamma_{1} \text { Sis. Empresarial }+\gamma_{2} \text { Gestión }+w \\
\text { Impacto Económico }=\emptyset_{0}+\emptyset_{1} \text { Sis. Empresarial }+\emptyset_{2} \\
\text { Mercadeo }+\emptyset_{3} \text { Infraestructura }+\emptyset_{4} \text { Política }+\emptyset_{5} \text { Impacto Social }+z
\end{gathered}
$$

\section{Resultados}

U na vez realizada la estimación se procede a evaluar la fiabilidad tanto del modelo externo como del interno. En el primer caso se evalúa la unidimensionalidad de los bloques, la cual se define como la capacidad de cada una de las variables observadas de participar en el cálculo de su respectiva variable latente - para este caso en el índice de cada variable-; la evaluación se realiza al examinar el valor de la carga — varianza explicada por cada variable observada - el alfa de Cronbach general de la variable y el rho de Dillon-Goldstein; ambos coeficientes muestran el grado de explicación general del bloque de indicadores sobre el índice calculado (Gil, Vargas y Gutiérrez, 2020).

La tabla 2 muestra los coeficientes estimados estadísticamente a fin de validar tanto el alfa de Cronbach como el rho de Dillon-Goldstein, los cuales deben estar por encima de 0,7. Como se muestra, el sistema cuenta con un alto grado de validez; excepto 
el alfa de la variable política, todos los coeficientes están por encima del valor de aceptación estadística. Sin embargo, según Latan y Richard (2017), se debe dar prioridad al valor obtenido para el rho de Dillon-Goldstein, ya que emplea las correlaciones entre variables observadas, al ser más preciso que el uso de covarianzas del alfa de Cronbach.

Tabla 2. Validación modelo externo

\begin{tabular}{|c|c|c|c|c|}
\hline Constructo & MVs & Carga & Alfa de Cronbach & DG rho \\
\hline \multirow{3}{*}{ Cultura } & CUL9 & 0,905 & 0,724 & 0,846 \\
\hline & CUL13 & 0,847 & & \\
\hline & CUL16 & 0,631 & & \\
\hline \multirow{3}{*}{ Ambiente } & AMB1 & 0,799 & 0,693 & 0,831 \\
\hline & AMB19 & 0,669 & & \\
\hline & AMB23 & 0,881 & & \\
\hline \multirow{8}{*}{ Infraestructura } & INF1 & 0,946 & 0,937 & 0,95 \\
\hline & INF3 & 0,919 & & \\
\hline & INF4 & 0,793 & & \\
\hline & INF7 & 0,9 & & \\
\hline & INF14 & 0,587 & & \\
\hline & INF16 & 0,885 & & \\
\hline & INF29 & 0,902 & & \\
\hline & INF31 & 0,634 & & \\
\hline \multirow{4}{*}{ Gestión } & GES32 & 0,96 & 0,856 & 0,907 \\
\hline & GES37 & 0,75 & & \\
\hline & GES40 & 0,95 & & \\
\hline & GES45 & 0,677 & & \\
\hline \multirow{3}{*}{ Política } & POL1 & 0,699 & 0,595 & 0,789 \\
\hline & POL2 & 0,913 & & \\
\hline & POL4 & 0,584 & & \\
\hline \multirow{7}{*}{ Empresarial } & EMP3 & 0,788 & 0,944 & 0,955 \\
\hline & EMP5 & 0,889 & & \\
\hline & EMP6 & 0,853 & & \\
\hline & EMP7 & 0,854 & & \\
\hline & EMP13 & 0,894 & & \\
\hline & EMP34 & 0,892 & & \\
\hline & EMP35 & 0,891 & & \\
\hline \multirow{2}{*}{ Mercadeo } & EST11 & 0,861 & 0,767 & 0,896 \\
\hline & EST14 & 0,934 & & \\
\hline \multirow{5}{*}{ Social } & SOC5 & 0,77 & 0,894 & 0,923 \\
\hline & SOC7 & 0,911 & & \\
\hline & SOC9 & 0,906 & & \\
\hline & SOC10 & 0,838 & & \\
\hline & SOC23 & 0,758 & & \\
\hline
\end{tabular}




\begin{tabular}{|c|c|c|c|c|}
\hline \multirow{4}{*}{ Económico } & ECO1 & 0,852 & 0,926 & 0,941 \\
\cline { 2 - 5 } & ECO3 & 0,921 & & \\
\cline { 2 - 5 } & ECO2 & 0,85 & & \\
\cline { 2 - 5 } & ECO12 & 0,889 & & \\
\cline { 2 - 5 } & ECO13 & 0,846 & & \\
\cline { 2 - 6 } & ECO17 & 0,712 & & \\
\cline { 2 - 5 } & ECO19 & 0,754 & & \\
\hline
\end{tabular}

Fuente. Elaboración propia.

Una vez validada la pertinencia de las variables observadas en la explicación de las variables latentes se procede a evaluar el modelo interno, para lo cual se evalúa la matriz de correlaciones cruzadas, la significancia estadística de los coeficientes estimados y el grado de determinación del sistema. En primera medida, se observa la matriz de correlaciones cruzadas, la cual evalúa el valor promedio de la varianza explicada por cada bloque de variables observadas sobre las variables latentes, con el fin de validar la fiabilidad estadística de los valores de la diagonal principal que deben ser los más altos; esto significa que, efectivamente, los constructos responden al objetivo de explicar una variable latente. La tabla 3 muestra que, efectivamente, el conjunto de variables manifiestas observadas - responde eficazmente a la explicación de su propio constructo.

Tabla 3. Correlaciones cruzadas

\begin{tabular}{|c|c|c|c|c|c|c|c|c|c|}
\hline & Cult. & Amb. & Infraest. & Gest. & Polít. & Empres. & Mercad. & Soc. & Econ. \\
\hline Cultura & $\mathbf{0 , 7 9 4}$ & & & & & & & & \\
\hline Ambiente & 0,513 & $\mathbf{0 , 7 8 3}$ & & & & & & & \\
\hline Infraestructura & 0,379 & 0,643 & $\mathbf{0 , 8 2}$ & & & & & & \\
\hline Gestión & $-0,613$ & $-0,684$ & $-0,742$ & $\mathbf{0 , 8 3 4}$ & & & & & \\
\hline Política & 0,388 & 0,437 & 0,526 & $-0,564$ & $\mathbf{0 , 7 3 2}$ & & & & \\
\hline Empresarial & 0,755 & 0,624 & 0,591 & $-0,692$ & 0,618 & $\mathbf{0 , 8 6 5}$ & & & \\
\hline Mercadeo & 0,704 & 0,632 & 0,417 & $-0,578$ & 0,505 & 0,658 & $\mathbf{0 , 8 9 7}$ & & \\
\hline Social & 0,626 & 0,599 & 0,599 & $-0,668$ & 0,693 & 0,693 & 0,511 & $\mathbf{0 , 8 3 7}$ & \\
\hline Económico & 0,738 & 0,63 & 0,564 & $-0,699$ & 0,629 & 0,803 & 0,64 & 0,681 & $\mathbf{0 , 8 3 2}$ \\
\hline
\end{tabular}

Fuente. Elaboración propia.

Como se mencionó en el apartado metodológico, la estimación por PLS-PM tiene un componente de regresión —-sistema c-, el cual permite validar las hipótesis propuestas por el modelo teórico. La tabla 4 presenta la hipótesis a validar, el valor del estimador - efecto directo de una variable sobre otra-, el valor $t$ calculado - permite dar validez estadística- y el resultado de aceptación o rechazo de la hipótesis.

Los resultados permiten validar siete de las diez hipótesis planteadas, de manera que se encuentra una relación positiva y estadísticamente significativa entre las variables; estos resultados se analizan a profundidad en el apartado de discusión. Por ahora vale la pena decir que las únicas relaciones no demostradas son las planteadas entre la infraestructura, el índice de impacto social y el mercadeo y la publicidad del destino turístico sobre el índice de impacto económico, lo que de forma preliminar permite intuir la existencia de condiciones que limitan el desempeño económico del turismo en las capitales colombianas. 
Tabla 4. Validación de hipótesis

\begin{tabular}{|c|c|c|c|c|}
\hline & Hipótesis & Efecto directo & t-value & Resultado \\
\hline $\mathbf{H}_{\mathbf{1}}$ & Cultura -> Empresarial & 0,699 & $5,03^{* * *}$ & Aceptado \\
\hline $\mathbf{H}_{\mathbf{2}}$ & Ambiente -> Empresarial & 0,265 & $1,91^{*}$ & Aceptado \\
\hline $\mathbf{H}_{3 \mathbf{a}}$ & Empresarial -> Mercadeo & 0,78 & $5,43^{* * *}$ & Aceptado \\
\hline $\mathbf{H}_{3 \mathrm{~b}}$ & Empresarial -> Social & 0,547 & $2,82^{* *}$ & Aceptado \\
\hline $\mathbf{H}_{3 \mathbf{c}}$ & Empresarial -> Económico & 0,776 & $5,00^{* * *}$ & Aceptado \\
\hline $\mathbf{H}_{\mathbf{4}}$ & Mercadeo -> Económico & 0,039 & 0,41 & Rechazado \\
\hline $\mathbf{H}_{\mathbf{5}}$ & Gestión -> Social & 0,37 & $1,90^{*}$ & Aceptado \\
\hline $\mathbf{H}_{\mathbf{6}}$ & Infraestructura -> Económico & $-0,049$ & $-0,47$ & Rechazado \\
\hline $\mathbf{H}_{7}$ & Política -> Económico & 0,18 & $1,77^{*}$ & Aceptado \\
\hline $\mathbf{H}_{\mathbf{8}}$ & Social -> Económico & 0,076 & 0,604 & Rechazado \\
\hline Los símbolos ${ }^{*},{ }^{* *}, \mathrm{y}^{* * *}$ denotan niveles de significancia de $10 \%, 5 \%, \mathrm{y} 1 \%$ respectivamente. \\
\hline
\end{tabular}

Fuente. Elaboración propia.

Con fines explicativos se realiza el análisis técnico-estadístico de uno de los efectos directos calculados. Para el particular se toma como ejemplo la hipótesis H1 Cultura -> Sistema Empresarial, la cual pretende evaluar la relación entre los componentes patrimoniales y culturales del destino sobre la generación de un clúster turístico; el valor estimado muestra cómo cada vez que el índice de condiciones culturales aumenta en una unidad, el índice referente al clúster turístico aumenta en 0,69 unidades. Esto significa que entre mejor aprovechamiento se haga del patrimonio en un territorio, existe mayor capacidad de generación y fortalecimiento de un sistema empresarial.

Finalmente, la tabla 5 muestra el grado de determinación de las variables, en el que el valor del R2 se analiza de la misma forma que en una regresión por mínimos cuadrados ordinarios (MCO), así como representa el grado de determinación de las variables latentes exógenas sobre la variable latente endógena. Los valores calculados superan el 0,6, lo que, según Garson (2016), muestra un grado alto de explicación.

Tabla 5. Grado de determinación variables endógenas

\begin{tabular}{|c|c|c|c|c|c|}
\hline & Tipo & R2 & $\begin{array}{c}\text { Comunalidad de } \\
\text { los bloques }\end{array}$ & $\begin{array}{c}\text { Redundancia } \\
\text { media }\end{array}$ & AVE \\
\hline Cultura & Exogenous & 0 & 0,645 & 0 & 0,645 \\
\hline Ambiente & Exogenous & 0 & 0,62 & 0 & 0,62 \\
\hline Infraestructura & Exogenous & 0 & 0,69 & 0 & 0,69 \\
\hline Gestión & Exogenous & 0 & 0,711 & 0 & 0,711 \\
\hline Política & Exogenous & 0 & 0,554 & 0 & 0,554 \\
\hline Empresarial & Endogenous & 0,804 & 0,751 & 0,604 & 0,751 \\
\hline Mercadeo & Endogenous & 0,608 & 0,807 & 0,49 & 0,807 \\
\hline Social & Endogenous & 0,764 & 0,704 & 0,538 & 0,704 \\
\hline Económico & Endogenous & 0,949 & 0,697 & 0,662 & 0,697 \\
\hline
\end{tabular}

Fuente. Elaboración propia. 
Los resultados obtenidos validan la generación de índices sintéticos de las nueve variables determinantes de la competitividad en el sector turístico para las ciudades capitales colombianas, lo cual permite obtener una alternativa metodológica del índice de competitividad turística. A su vez, se validan siete de las diez hipótesis de la relación planteadas, lo que confirma las correspondencias teóricas planteadas por estudios como los de Dwyer y Kim (2003), Dwyer, Livaic y Mellor (2003) y Enright y Newton (2004). También se valida la existencia de ventajas comparativas y competitivas en el turismo; la validación de hipótesis se resume en la figura 2.

Figura 2. Modelo estimado

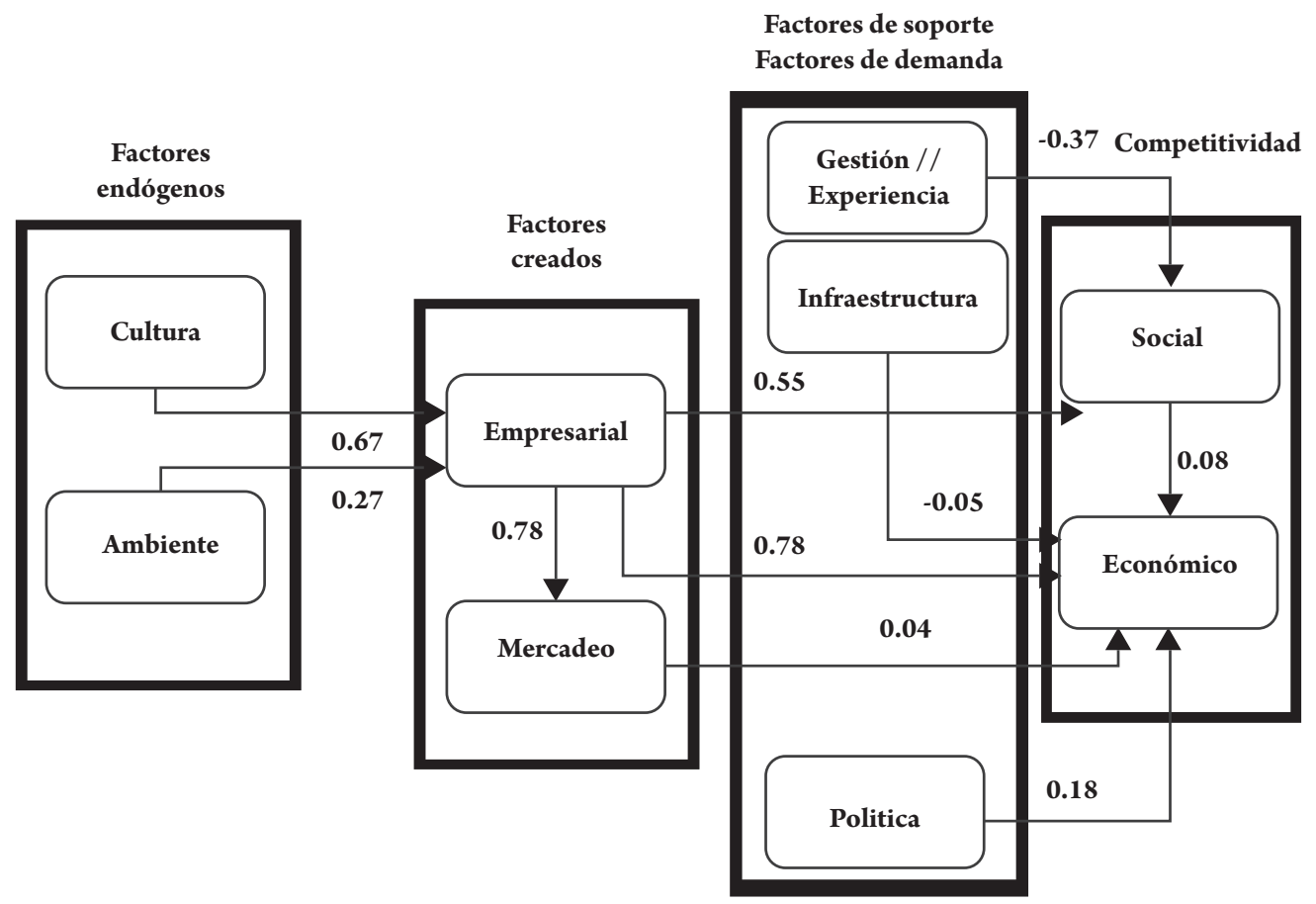

Fuente. Elaboración propia.

\section{Discusión de resultados}

ב discusión de resultados se divide en dos secse plantea el análisis de los índices de competitividad de las nueve variables consideradas en el estudio, en el que se identifica la existencia de diferencias entre destinos turísticos y potencialidades sectoriales a partir de evaluar el estado de factores endógenos: creados, de soporte, demanda e impacto en la competitividad. Por otra, se procede a interpretar las relaciones de causalidad planteadas como hipótesis y validadas mediante la estimación del modelo interno de PLS-PM; la validación de estas relaciones permite identificar condiciones de política pública y estrategias a implementar en la cadena turística con miras a mejorar los índices y tener mayor grado de impacto en la competitividad del destino. Con fines analíticos se tomarán las ciudades con puntaje más alto para cada índice y se comparan con Tunja y Popayán como ciudades intermedias, así como con las ciudades de menor desempeño. 
La tabla 6 presenta los índices calculados para cada una de las dimensiones, además de un valor promedio del índice de competitividad turística para las 21 ciudades capitales evaluadas. Los resultados muestran que, en general, Bogotá cuenta con ventajas comparativas en los factores endógenos culturales ${ }^{12}$ que la posicionan como la ciudad con mejor uso y acoplamiento del patrimonio en el clúster empresarial del turismo, seguida de Cartagena y Medellín. Cabe considerar que, aunque ciudades como Popayán o Tunja, reconocidas por sus eventos culturales y su tradición patrimonial, se encuentran en sexto y décimo sexto lugar, respectivamente, esto puede significar que el impacto generado por los bienes de interés cultural (BIC) y los eventos culturales no es el esperado. Las ciudades con menor desempeño en el índice de cultura y patrimonio son Puerto Inírida y Florencia.

En cuanto a los factores endógenos asociados a la naturaleza y al medio ambiente — calidad del aire y el agua, $y$ menor grado de conflictos ambientales-, Medellín tiene el índice más alto, seguida de Barranquilla y Cartagena. En este punto Tunja se ubica en el cuarto lugar, mientras que Popayán se encuentra en el décimo segundo lugar, lo que permite inferir que la calidad del agua y el aire de la ciudad es un punto negativo evaluado por los turistas. Nuevamente, se encuentra Puerto Inírida en el último lugar del ranquin, esta vez acompañada de Mitú.

Con relación a los factores creados, el índice de evaluación del sistema empresarial ${ }^{13}$ posiciona a Bogotá como la ciudad con mejor calificación, seguida de Cartagena y Medellín. Esta dimensión muestra altas deficiencias en el caso de las ciudades intermedias Tunja y Popayán, las cuales ocupan el puesto décimo quinto y décimo sexto, respectivamente; se evidencia un problema en la cadena primaria y de forma específica en la oferta de hoteles y restaurantes con registro nacional de turismo (RNT). En el último lugar se encuentran de nuevo Puerto Inírida y Mitú.
La gestión del mercadeo y la publicidad del destino evalúa la participación de empresarios en ferias nacionales e internacionales, así como por la publicidad del territorio en medios virtuales de promulgación. El índice muestra que las ciudades con mejor nivel de mercadeo son Barranquilla, Cali y Medellín. Tunja se encuentra en el décimo séptimo puesto del ranquin, lo cual significa que en esta ciudad los procesos de marketing del destino son muy bajos frente a las demás capitales del país; en este mismo nivel se encuentran Puerto Inírida, Mitú y Florencia, entre otras. Este índice es el de mayor debilidad para ciudades intermedias y pequeñas.

Los factores de soporte considerados son infraestructura y sistema político asociado al turismo. En estas dimensiones se evalúan temas tales como accesibilidad al destino, conexión entre ciudades, acceso a servicios públicos, tiendas y políticas públicas sectoriales en turismo. El índice de infraestructura de soporte al turismo posiciona a Bogotá, Medellín y Bucaramanga como las ciudades con mejor accesibilidad e infraestructura general para la prestación de servicios turísticos. Popayán y Tunja se posicionan en el décimo tercer y décimo sexto lugar, respectivamente; la evaluación muestra que, aunque la accesibilidad a la ciudad es buena, la prestación de servicios públicos y empresas de soporte al turismo tienen debilidades.

En cuanto al soporte brindado por instituciones públicas, principalmente alcaldías y gobernaciones, se destacan las políticas generadas por Bogotá, Cali y Santa Marta. Estas ciudades se tratan de posicionar como destinos turísticos consolidados a través de la inclusión de políticas sectoriales en planes de desarrollo y de inversiones. Popayán se encuentra a mitad de tabla en el décimo puesto, mientras Tunja presenta una deficiente acción gubernamental, lo que posiciona a la ciudad en el décimo noveno puesto, de modo que se encuentra por encima solo de Puerto Inírida y Mitú.

\footnotetext{
${ }^{12}$ Atractivos categorizados como bienes de interés cultural, festivales y eventos culturales.

${ }^{13}$ Asociado a prestación de servicios turísticos directos — hoteles, restaurantes, agencias de viaje-.
} 
La gestión del destino evalúa la percepción y los indicadores de seguridad, accidentalidad, violencia contra los turistas y existencia de policía de turismo. Bogotá, Medellín y Cali se posicionan en primer lugar; Popayán con bajos niveles de policía para el turismo se encuentra en el décimo segundo lugar, mientras Tunja, con buenas percepciones de seguridad y de la gestión policiaca se evalúa de manera negativa $y$, por tanto, se encuentra en el décimo noveno lugar superado por Mitú y Puerto Inírida.

Los índices de impacto social y económico evalúan la importancia del turismo en la generación de empleo, mejora del bienestar y aporte al crecimiento económico de los territorios. En cuanto al impacto social representado, principalmente, por la generación de empleo formal, Bogotá, Medellín y Cartagena son las ciudades que encabezan el ranquin. Tunja y Popayán se encuentran en el décimo primer y décimo segundo lugar, respectivamente, con miras a un índice medio que muestra cómo los servicios turísticos los prestan empresas o personas en estado de informalidad laboral o con condiciones laborales no fijas. En este índice de nuevo se encuentran Mitú y Puerto Inírida.

En cuanto al aporte al crecimiento económico y la estabilidad empresarial, de nuevo Bogotá, Cartagena y Medellín están en los primeros puestos. Tunja se encuentra en el décimo octavo puesto, de modo que se identifica un bajo aporte del turismo a la economía. Además, este índice considera la inversión privada en turismo y el consumo, así como el valor agregado generado por los turistas durante su estadía, por lo que se puede pensar en un déficit en la ciudad para generar eslabonamientos y procesos de demanda turística.

Por último, se presenta el valor promedio de los índices, el cual se puede entender como el índice general de competitividad turística. Este muestra el aprovechamiento de ventajas tanto comparativas como competitivas por parte de los territorios. En el top tres de destinos competitivos a nivel nacional se encuentran Bogotá, Medellín y Cartagena; en un nivel medio de competitividad se encuentran Manizales, Popayán e Ibagué. En un nivel bajo Pasto, Tunja y Riohacha, las cuales se posicionan como ciudades con bajos niveles de competitividad en las que a pesar de existir recursos patrimoniales y potencial turístico no hay un aprovechamiento de oportunidades. Finalmente, en un nivel muy bajo están Florencia, Puerto Inírida y Mitú, ciudades con bajísimo potencial turístico.

Tabla 6. Índices calculados para las ciudades capitales

\begin{tabular}{|c|c|c|c|c|c|c|c|c|c|c|}
\hline Ciudad & Cult. & Amb. & Infraest. & Gest. & Polít. & Empres. & Mercad. & Soc. & Econ. & Promedio \\
\hline Bogotá & 2,81 & 0,9 & 1,15 & 2 & 1,7 & 2,2 & 1,4 & 2,01 & 2,32 & 1,83 \\
\hline Medellín & 1,23 & 1,5 & 0,81 & 1,48 & 0,8 & 1,21 & 1,59 & 1,59 & 1,44 & 1,29 \\
\hline Cartagena & 1,32 & 1,2 & 0,44 & 0,71 & 0,86 & 1,68 & 0,67 & 1,17 & 1,73 & 1,09 \\
\hline Cali & 0,8 & 0,72 & 0,47 & 1,28 & 0,99 & 0,79 & 1,66 & 0,66 & 0,81 & 0,91 \\
\hline Barranquilla & 0,96 & 1,45 & 0,45 & 0,49 & 0,4 & 0,87 & 2,16 & $-0,28$ & 0,69 & 0,80 \\
\hline Pereira & 0,14 & 0,6 & 0,3 & $-0,01$ & 0,4 & 0,58 & 1,03 & 0,62 & 0,63 & 0,48 \\
\hline Santa Marta & 0,39 & 0,42 & 0,43 & 0,23 & 0,99 & 0,49 & $-0,39$ & 0,15 & 0,53 & 0,36 \\
\hline Bucaramanga & 0,1 & 0,24 & 0,61 & 0,12 & $-0,18$ & 0,57 & 0,43 & 0,47 & 0,41 & 0,31 \\
\hline Manizales & $-0,23$ & $-0,65$ & 0,26 & $-0,23$ & 0,4 & 0,57 & $-0,06$ & 0,58 & $-0,09$ & 0,06 \\
\hline Popayán & 0,62 & 0,05 & 0,25 & $-0,04$ & 0,4 & $-0,78$ & 0,16 & 0,01 & $-0,46$ & 0,02 \\
\hline Ibagué & $-0,06$ & $-0,42$ & 0,22 & $-0,11$ & $-0,91$ & $-0,05$ & $-0,39$ & 0,86 & $-0,6$ & $-0,16$ \\
\hline Cúcuta & $-0,32$ & $-0,07$ & 0,1 & $-0,11$ & $-0,48$ & $-0,02$ & $-0,87$ & $-0,52$ & 0,13 & $-0,24$ \\
\hline Armenia & $-1,06$ & 0,3 & 0,31 & 0,45 & $-0,91$ & $-0,67$ & $-0,87$ & 0,65 & $-0,44$ & $-0,25$ \\
\hline
\end{tabular}




\begin{tabular}{|c|c|c|c|c|c|c|c|c|c|c|}
\hline Neiva & $-0,48$ & $-0,54$ & 0,19 & $-0,16$ & $-0,18$ & $-0,35$ & $-0,87$ & $-0,52$ & $-0,61$ & $-0,39$ \\
\hline Villavicencio & $-1,05$ & $-0,93$ & 0,32 & 0 & 0,8 & $-0,45$ & $-0,87$ & $-1,06$ & $-0,41$ & $-0,41$ \\
\hline Pasto & $-0,47$ & $-0,6$ & 0,29 & 0,06 & $-0,18$ & $-0,78$ & $-0,87$ & $-0,81$ & $-0,4$ & $-0,42$ \\
\hline Tunja & $-0,74$ & 0,83 & 0,12 & $-0,54$ & $-0,91$ & $-0,77$ & $-0,87$ & $-0,06$ & $-0,83$ & $-0,42$ \\
\hline Riohacha & $-0,95$ & $-0,57$ & $-0,69$ & $-0,34$ & 0,27 & $-0,97$ & $-0,87$ & $-0,83$ & $-0,73$ & $-0,63$ \\
\hline Florencia & $-1,11$ & 0,06 & $-0,24$ & $-0,52$ & $-0,18$ & $-1,18$ & $-0,39$ & $-1,41$ & $-1,18$ & $-0,68$ \\
\hline $\begin{array}{c}\text { Puerto } \\
\text { Inírida }\end{array}$ & $-1,39$ & $-2,32$ & $-2,94$ & $-2,55$ & $-0,91$ & $-1,4$ & $-0,87$ & $-1,74$ & $-1,26$ & $-1,71$ \\
\hline Mitú & $-0,53$ & $-2,16$ & $-2,84$ & $-2,21$ & $-3,13$ & $-1,55$ & $-0,87$ & $-1,54$ & $-1,7$ & $-1,84$ \\
\hline
\end{tabular}

Fuente. Elaboración propia.

Además de evaluar el desempeño competitivo de las ciudades capitales, el sistema calculado permite validar las hipótesis de relación planteadas en el apartado teórico. El resultado más representativo muestra que, tal como lo plantean Dwyer, Livaic y Mellor (2003), Mazanec, Wöber y Zins (2007), así como Alberti y Giusti (2012), existe un efecto indirecto sobre la competitividad de los destinos. Esta relación se da mediante la intermediación de la estructura empresarial asociada a la cadena de valor turística. De esta forma, se verifica la hipótesis principal según la cual un territorio con aprovechamiento de sus ventajas patrimoniales mejora su competitividad.

Así, se valida una relación entre el aprovechamiento de las ventajas comparativas patrimoniales por parte de la cadena de valor del sector turístico. Se encuentra que, en general, para las ciudades capitales colombianas existe una tendencia a la conformación de un clúster turístico, así como se evidencia que para las primeras cinco ciudades del ranquin -Bogotá, Medellín, Cartagena, Cali y Barranquilla - existen estrategias adecuadas de mercadeo del destino. Esto implica que los canales virtuales se usan de una forma más eficiente que en las demás ciudades; adicionalmente, se encuentra la generación de ventajas competitivas en estos destinos a partir de la mayor atracción generada en ferias turísticas nacionales e internacionales.
Una segunda fuente de generación de ventajas comparativas en el territorio, además del patrimonio, es el medio ambiente. Las hipótesis validadas muestran que las condiciones naturales del destino favorecen la consolidación de la cadena de valor turística de un territorio y cómo este genera procesos de crecimiento y desarrollo. Ahora bien, el efecto del ambiente es menor que el efecto del patrimonio, lo que significa que, al menos para las capitales colombianas, el patrimonio es la principal fuente de competitividad en términos de turismo.

Los resultados muestran que la infraestructura no está preparada para sostener la cadena turística y no existe una capacidad en términos de transporte, accesibilidad y estado de carreteas que permita a los turistas disfrutar de los atractivos. A esto se adiciona una pobre gestión turística por parte del sector público, pues se encuentra que los destinos que no cuentan con políticas públicas sectoriales específicas para el turismo no alcanzan altos niveles de competitividad. De esto se desprende una posible condición que podría mejorar los estándares de competitividad: la formulación de políticas y de planes especiales dirigidos al apoyo al sector es una condición de soporte fundamental para competir, así como la condición de infraestructura es necesaria en procura de la generación de valor agregado. 
Tabla 7. Efectos entre variables

\begin{tabular}{|l|c|c|c|}
\hline \multicolumn{1}{|c|}{ Relaciones } & Efecto directo & Efecto indirecto & Efecto total \\
\hline Cultura -> Empresarial & 0,699 & 0 & 0,699 \\
\hline Cultura -> Mercadeo & 0 & 0,545 & 0,545 \\
\hline Cultura -> Social & 0 & 0,3827 & 0,382 \\
\hline Cultura -> Económico & 0 & 0,5932 & 0,593 \\
\hline Ambiente -> Empresarial & 0,2653 & 0 & 0,265 \\
\hline Ambiente -> Mercadeo & 0 & 0,2069 & 0,206 \\
\hline Ambiente -> Social & 0 & 0,1452 & 0,145 \\
\hline Ambiente -> Económico & 0 & 0,2252 & 0,225 \\
\hline Infraestructura -> Económico & $-0,0496$ & 0 & $-0,049$ \\
\hline Gestión -> Social & 0,37 & 0 & 0,37 \\
\hline Gestión -> Económico & 0 & 0,0282 & 0,028 \\
\hline Política -> Económico & 0,1813 & 0 & 0,181 \\
\hline Empresarial -> Mercadeo & 0,7797 & 0 & 0,779 \\
\hline Empresarial -> Social & 0,5474 & 0 & 0,547 \\
\hline Empresarial -> Económico & 0,7764 & 0,0722 & 0,848 \\
\hline Mercadeo -> Económico & 0,039 & 0 & 0,039 \\
\hline Social -> Económico & 0,0762 & 0 & 0,076 \\
\hline
\end{tabular}

Fuente. Elaboración propia.

\section{Conclusiones}

T a competitividad de los destinos turísticos ha Lido estudiada desde la perspectiva de entender sus determinantes. Dwyer, Livaic y Mellor (2003), Dwyer y Kim (2003) y Enright y Newton (2005) condicionan el desempeño turístico de los territorios en función a una serie de capacidades endógenas, tales como el clima o las condiciones culturales; factores creados manifestados por las empresas generadoras del clúster turístico y la publicidad o el mercadeo del destino; factores de apoyo asociados a la infraestructura, las condiciones políticas y sociales; y, finalmente, a las condiciones de demanda asociadas a la experiencia del turista.

El estudio de los determinantes de la competitividad permite establecer dos análisis evaluados en este documento. Por un lado, se realiza una estimación de los índices de desempeño en cada una de las variables: cultura, ambiente, infraestructura, gestión del territorio, política, cadena empresarial, mercadeo, impacto social e impacto económico. Se encuentra que Bogotá, Medellín y Cartagena son las «más competitivas» en temas turísticos en el país, dado el buen desempeño que tienen en dimensiones como, por ejemplo, lo empresarial y lo político, lo cual les permite aprovechar las capacidades propias representadas en su cultura y su clima.

Por otra parte, se llegó a una aproximación de la medición de las relaciones entre las variables mencionadas, con el fin de comprobar la hipótesis fundamental de que «el patrimonio cultural sí tiene un efecto sobre el desempeño social y económico de un territorio». También que la relación entre el clúster turístico y los factores de soporte, como, por ejemplo, el Estado y la infraestructura, tienen una incidencia directa sobre la generación de ventajas competitivas territoriales. 
La relación entre el clúster de turismo y el desempeño económico de las ciudades es la más alta - $0,84-$, seguida de la relación entre las empresas y el mercadeo - 0,77 - Esto permite señalar que las ciudades capitales, en general, realizan un correcto aprovechamiento de sus recursos patrimoniales y consiguen una estructura de sistemas en la que empresas prestadoras de servicios turísticos visibilizan el territorio y de forma directa se dan procesos de crecimiento económico.

A pesar de que la relación entre patrimonio y la generación de clúster turístico es alta $-0,7-$, se encuentran casos específicos de ciudades que, a priori, cuentan con buenas capacidades endógenas representadas por su cultura, como, por ejemplo, Tunja y Popayán, que tienen un pobre desempeño en los factores de soporte a la cadena, lo cual las lleva a desaprovechar las ventajas comparativas patrimoniales y a no tener un buen desempeño turístico.

En general, se valida que una correcta gestión del territorio le permite mejorar su competitividad. El factor clave al plantear relaciones entre la competitividad y el patrimonio es la intermediación de la cadena de valor del turismo. Son las empresas las que aprovechan las condiciones de ventajas patrimoniales del destino y obtienen provecho a partir del marketing y la publicidad. Una condición clave que determina la capacidad de competir por parte de las ciudades es la participación del gobierno, dado que se requiere de formulación de políticas públicas que conduzcan a la formación de la infraestructura de acceso y transporte de las ciudades para garantizar un buen desempeño en el sector.

La influencia del patrimonio sobre la competitividad de los destinos requiere de la colusión entre distintos sectores, en particular, se da relevancia a la capacidad del Estado de asegurar un ambiente político favorable para la acción del sector privado, el cual debe procurar la construcción de clústeres que impulsen los procesos de innovación. Por su parte, la sociedad civil debe actuar como un agente de soporte que, al igual que la academia, represente la exploración de oportunidades y el mantenimiento de esas condiciones a explotar.
Si bien es cierto que se consigue una ampliación del ICTRC, de manera que se llegan a determinar las relaciones entre las variables estudiadas, es un avance en la comprensión de un problema que seguramente queda abierto a futuras investigaciones que permitan formular propuestas de consolidación del país y de regiones específicas como un destino turístico patrimonial.

\section{Referencias}

Alberti, F. G.; Giusti, J. D. (2012). Cultural heritage, tourism and regional competitiveness: the Motor Valley cluster. City, Culture and Society, 3(4), 261-273. DOI: https://doi. org/10.1016/j.ccs.2012.11.003

Buhalis, D. (2001). Tourism in Greece: strategic analysis and challenges. Current Issues in Tourism, 4(5), 440-480. DOI: https://doi.org/10.1080/13683500108667898

Centro de Pensamiento Turístico de Colombia. (2019a). Índice de competitividad turística regional de Colombia ICTRC: ciudades capitales y municipios con vocación turística 2019. Recuperado de https://bit.ly/3CaVW7j

Centro de Pensamiento Turístico de Colombia. (2019b). Índice de competitividad turística regional de Colombia ICTRC: Departamentos 2019. Recuperado de https://bit.ly/3fvhQZh

Centro de Pensamiento Turístico de Colombia. (2020). Centro de Pensamiento Turístico de Colombia - CPTUR. Recuperado de https://cptur.org/

Cho, D. S. (1998). From national competitiveness to bloc and global competitiveness. Competitiveness Review, 8(1), 11-23. DOI: https://doi.org/10.1108/eb046358

Cohen, E. (1988). Authenticity and commoditization in tourism. Annals of Tourism Research, 15, 271-286. DOI: https://doi. org/10.1016/0160-7383(88)90028-X

Crouch, G. I.; Ritchie,J.R. B. (2006). Destination competitiveness. En L. Dwyer; P. Forsyth (Eds.) International handbook on the Economics of Tourism. (419-433). Northampton: Edward Elgar Publishing Limited.

Cuervo, A. (1993). El papel de la empresa en la competitividad. Papeles de Economía Española, (56), 363-378.

Dwyer, L.; Forsyth, P.; Rao, P. (2000). The price competitiveness of travel and tourism: a comparison of 19 destinations. Tourism Management, 21(1), 9-22. DOI: https://doi.org/10.1016/ S0261-5177(99)00081-3 
Dwyer, L.; Kim, C. (2003). Destination competitiveness: determinants and indicators. Current Issues in Tourism, 6(5), 369414. DOI: https://doi.org/10.1080/13683500308667962

Dwyer, L.; Livaic, Z; Mellor, R. (2003). Competitiveness of Australia as a tourist destination. Journal of Hospitality and Tourism Management, 10(1), 60-78.

Enright, M. J.; Newton, J. (2004). Tourism destination competitiveness: a quantitative approach. Tourism Management, 25(6), 777-788. https://doi.org/10.1016/j. tourman.2004.06.008

Enright, M. J.; Newton, J. (2005). Determinants of tourism destination competitiveness in Asia Pacific: comprehensiveness and universality. Journal of Travel Research, 43(4), 339-350. DOI: https://doi.org/10.1177/0047287505274647

Esser, K.; Hillebrand, W.; Messner, D.; Meyer-Stamer, J. (1996). Competitividad sistémica: nuevo desafío para las empresas y la política. Revista de la CEPAL, (59), 39-53. DOI: https:// doi.org/10.18356/183846f0-es

Garson, D. G. (2016). Partial least squares (PLS-SEM)-regression and structural equation models. Asheboro: Statistical Associates Publishers.

Gil, J.; Vargas, E.; Gutiérrez, J. (2020). Capital intelectual, comportamiento innovador y ventaja competitiva en pymes: relaciones de influencia en hoteles de Boyacá (Colombia). Revista Espacios, 41(31), 102-118. Recuperado de https://bit. ly/37pgenr

Hesmondhalgh, D. (2007). The cultural industries (3a ed.). Londres: Sage.

Hong, W. C. (2009). Global competitiveness measurement for the tourism sector. Current Issues in Tourism, 12(2), 105-132. https://doi.org/10.1080/13683500802596359

Ibarra-Armenta, C. I.; Trejo-Nieto, A. B. (2014). Competencia territorial: un marco analítico para su estudio. Economía Sociedad y Territorio, 14(44), 49-78. DOI: https://doi. org/10.22136/est00201430

Instituto Distrital de Turismo de Bogotá. (2014). Indicadores de competitividad del sector turistíco de Bogotá: Una propuesta en la perspectiva de la competitividad sistémica. Recuperado de https://bit.ly/3fsyEjG

Kresl, P. K., \& Singh, B. (1999). Competitiveness and the urban economy: Twenty-four large US Metropolitan areas. Urban Studies, 36(5-6), 1017-1027. DOI: https://doi. org/10.1080/0042098993330

Latan, H.; Richard, N. (2017). Partial least squares path modeling: basic concepts, methodological issues and applications. Cham: Springer. DOI: https://doi.org/10.1007/978-3-319-64069-3

Mazanec, J. A.; Wöber, K.; Zins, A. H. (2007). Tourism destination competitiveness: from definition to explanation? Journal of Travel Research, 46(1), 86-95. DOI: https://doi. org/10.1177/0047287507302389
Murphy, P.; Pritchard, M. P.; Smith, B. (2000). The destination product and its impact on traveller perceptions. Tourism Management, 21(1), 43-52. DOI: https://doi.org/10.1016/ S0261-5177(99)00080-1

Organización Mundial de Turismo. (2005). Indicadores de desarrollo sostenible para los destinos turísticos. Guía práctica. Recuperado de https://bit.ly/37jMD72

Porter, M. E. (1980). Competitive strategy. Nueva York: Free Press.

Porter, M. E. (1985). Ventaja competitiva. Ciudad de México: Cecsa.

Porter, M. E. (1990). The competitive advantage of nations. Nueva York: Free Press. DOI: https://doi.org/10.1007/978-1-34911336-1

Porter, M. E. (2008). Las cinco fuerzas competitivas de Michael E. Porter. Harvard Business Review. América Latina, 1-18. Recuperado de https://bit.ly/3Cg0Kbs

Ritchie, J. R. B.; Crouch, G. I. (2003). The competitive destination. A sustainable tourism perspective. Wallingford: CABI Publishing. DOI: https://doi.org/10.1079/9780851996646.0000

Sánchez, G. (2013). PLS Path Modeling with R. Berkeley: Trowchez Editions. Recuperado de https://bit.ly/3ilGZaN

Sasaki, M. (2010). Urban regeneration through cultural creativity and social inclusion: rethinking creative city theory through a Japanese case study. Cities, 27(suppl. 1), S3-S9. DOI: https:// doi.org/10.1016/j.cities.2010.03.002

Scott, A. J. (1997). The cultural economy of cities. International Journal of Urban and Regional Research, 21 (2), 323-339. DOI: https://doi.org/10.1111/1468-2427.00075

Spence, M.; Hazard, H. A. (1988). International competitiveness. Cambridge: Ballinger.

Vasenska, I. (s. f.). The liaison between culture, tourism, tourism destination competitiveness, attractiveness and image. Recuperado de https://bit.ly/2TQdaWg

Young, J. (1986). Global competition-the new reality: results of the president's commission on industrial competitiveness. En R. Landau; N. Rosenberg (Eds.) The Positive Sum Strategy: Harnessing Technology for Economic Growth. (501-509). Washington: The National Academies Press. DOI: https:// doi.org/https://doi.org/10.17226/612 


\section{Anexo}

Tabla A1. Variables observadas

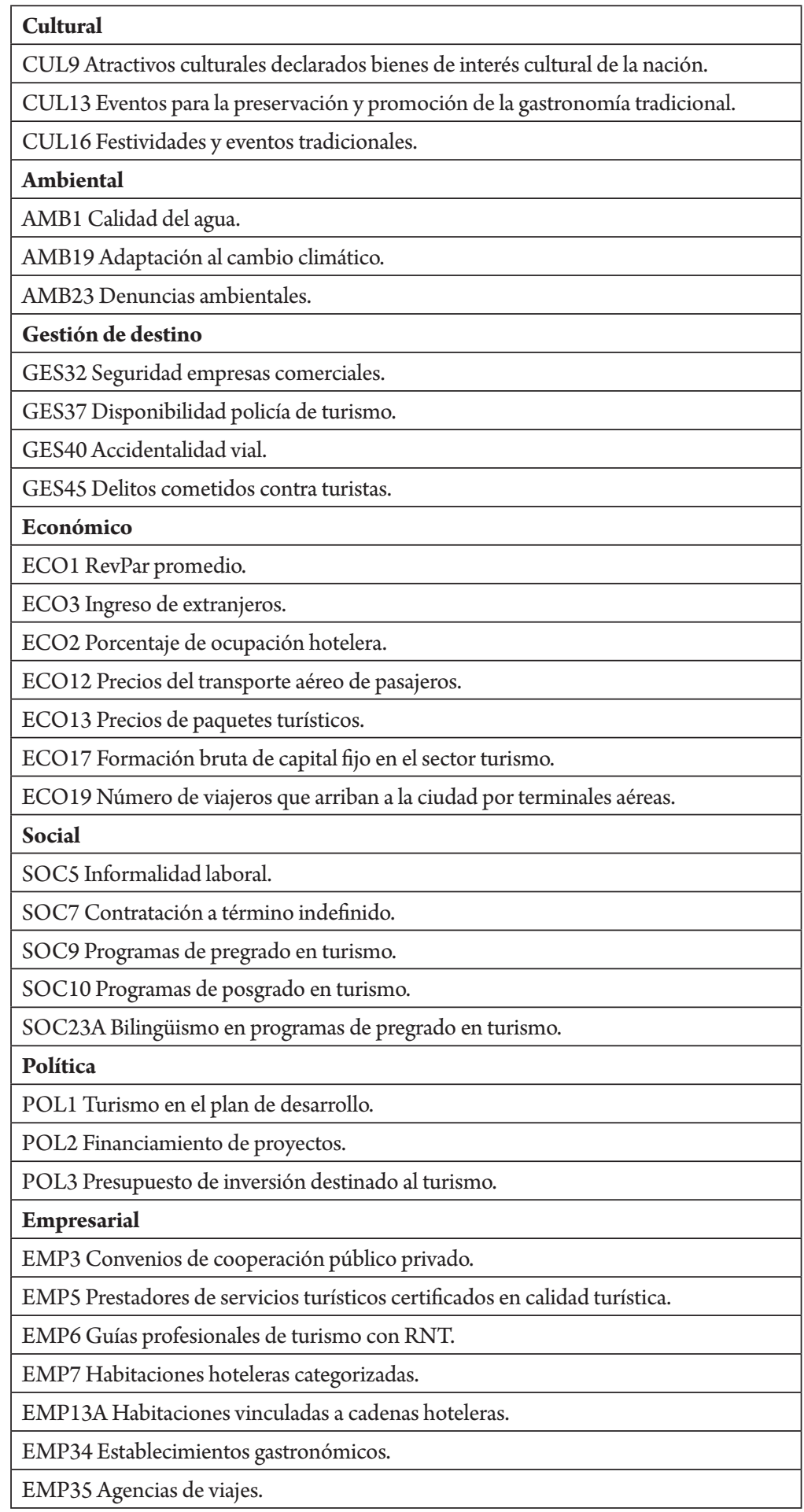


El papel del turismo patrimonial en el índice de competitividad turística regional de Colombia: una evaluación de las relaciones mediante PLS-PM

\begin{tabular}{|l|}
\hline Estrategia de mercadeo \\
\hline EST11 Participación en ferias internacionales especializadas en turismo. \\
\hline EST14 Promoción en medios virtuales. \\
\hline Infraestructura \\
\hline INF1 Índice de penetración del servicio de internet banda ancha. \\
\hline INF3 Velocidad de conexión a internet por banda ancha. \\
\hline INF4 Llamadas caídas en la red de telefonía móvil. \\
\hline INF7 Disponibilidad de camas hospitalarias. \\
\hline INF14 Cobertura del servicio de energía eléctrica. \\
\hline INF16 Terminales de transporte terrestre. \\
\hline INF29 Capacidad hotelera. \\
\hline INF31 Disponibilidad de ambulancias. \\
\hline
\end{tabular}

Fuente. Adaptado del Centro de Pensamiento Turístico de Colombia, 2019a. 
is 